\title{
[gw22-e0649] INTERVENTIONAL THERAPY STUDY ON USING MICRO-CATHETER JOINT WITH GUIDE WIRE PRIVATE FOR OCCLUSION IN CORONARY ARTERY CHRONIC TOTAL OCCLUSION
}

Xie Dongming, Liao Xiangzhong, Zhou Aiqing Department of Cardiology, Affiliated Hospital of Gannan Medical College, China

10.1136/heartjnl-2011-300867.474

Objective To evaluate the feasibility and safety of using micro-catheter joint with occlusion private guide wire for patients with coronary artery chronic total occlusion (CTO) intervention.

Method Twelve patients were diagnosis as coronary CTO by radial artery angiography, and the disease itself or the opposite side had coronary collateral circulations. Prorsad posted in soft guide wire to the proximal occlusion, extended the soft guide wire, then posted in micro-catheter to the proximal occlusion and withdrawed the soft guide wire. Using micro-catheter to change different CTO special guide wires, fine controlled guide wire direction, adjusted the guide wire head-end hardness and then did highly selective angiography by micro-catheter. After the occlusion, did balloon dilatation and stenting.

Results Eleven cases were successful to do percutaneous transluminal coronary angioplasty (PTCA) and stenting, and one case was failed. Intraoperative, there were no complications both coronary artery dissection and perforation.

Conclusion Using micro-catheter joint with guide wire private for occlusion, is a safe and effective method in coronary artery CTO intervention. 